\title{
YOUTH, SOCIAL CLASS AND PRIVILEGE IN THE ANTIPODES: TOWARDS A NEW RESEARCH AGENDA FOR YOUTH SOCIOLOGY
}

France, A., Roberts, S., \& Wood, B. Youth, social class and privilege in the antipodes: Towards a new research agenda for youth sociology. Journal of Sociology, O(0), 1440783318786580. doi:10.1177/1440783318786580

Pre-print final document May 2018.

\section{Abstract}

In recent decades, youth sociology in the antipodes has paid inadequate attention to social class and lacked focus on the question of privilege. We critique narrow and utilitarian ways that social class has been analysed in the antipodes, arguing that the primary focus on the marginalised has overlooked the significance of privilege in perpetuating and maintaining social reproduction. While there is some evidence of a growing interest in the subjective experiences of class, we propose a new research agenda for youth sociology in the antipodes which includes a much more explicit focus on class and approaches which recognise the complex, longitudinal and intersectional nature of class and its relationship with privilege. As an example of how such a research agenda could be developed, we conclude by drawing upon the work of Pierre Bourdieu to show how his theoretical tools can provide deeperinsights into how privilege operates through institutional and intergenerational processes which then serves to maintain advantage and disadvantage in young people's lives.

\section{Keywords age groups, Australia, Bourdieu, privilege, social class, NewZealand, youth}




\section{Introduction}

That Australia and New Zealand are 'classless' societies is a perception strongly held in the public imagination. A commonly held belief by members of these two settler societies was that, unlike the UK, social class hierarchies would not feature in the newly emerging colonies. This perspective remains prominent in contemporary political and (even) academic discourses in both countries (France and Roberts, 2017). This is surprising given the levels of income and wealth inequality in both countries. For example, New Zealand's wealthiest top $1 \%$ own $16 \%$ of total wealth (NZ\$77 billion), the top $10 \%$ own over $50 \%$, and the bottom $50 \%$ own just $5 \%$ of wealth (Rashbrooke, 2015). A similar pattern exists in Australia, where the top $10 \%$ owns $45 \%$ of all wealth. The gap in Australia has also been increasing, with the top quintile's wealth growing $28 \%$ over 8 years, while the bottom quintile's wealth increased by only $3 \%$ (Australian Council of Social Services, 2015). Despite its visibility, such patterns of inequality are rarely theorised or explained in terms of social class.

Youth sociology emerged in the past with a strong focus on social class. However, we suggest that in recent times this has been under-developed and overlooked. In this paper, we set out a 'new' research agenda for youth studies, proposing that class matters significantly and must be 'put back on the map' in terms of explaining people's lives in the antipodes. In addition, we suggest that the prevailing focus on 'looking downwards' (to the proletariat) in social class analysis has failed to see the interconnected nature of the creation of elites and the often-invisible

maintenance of wealth through the life course. Our paper joins others (see e.g. Savage, 2015; Savage \& Williams, 2008; Reeves et al 2017) arguing for a much wider configuration of class analysis, including a focus on privilege and elites, to deepen our understandings of how inequalities are perpetuated. This requires robust theoretical 
engagement that is sufficiently agile to account for emerging expressions of social

class, but also ongoing influences that continue to affect young people's everyday lives. Finally, we argue that more intentional and innovative methodological strategies need to be developed if youth sociology is able to capture the complex ways that class manifests itself today.

We begin by outlining how class has historically been perceived and theorised in the antipodes, especially in relation to the young. We demonstrate how, despite some exceptions that focused on marginalised youth and those in elite schooling, class has faded in significance for antipodes-based youth researchers in recent decades. We then advocate for an enhanced class analysis of youth to consider how privilege is invisible, yet influential in socially reproducing class inequality, by highlighting how many of these processes are embedded and legitimised in institutional practices. We also draw attention to key methodological challenges when examining youth privilege and conclude by proposing the usefulness of Pierre Bourdieu's theoretical approach to help understand these processes.

\section{Class in the Antipodes}

New Zealand's formation as a state, while embracing traditional British values of 'hard work' and nationhood with clear allegiances to the 'mother country', was viewed as unique in "...its absence of class difference, its affluence and equality, its affable, sincere sociability, its untroubled 'race relations'” (During, 1998: 34). This is perhaps no better symbolised than through the sport of rugby. Contrasting rugby's associations with the upper class, public schooling system in England, New Zealanders often view rugby as "a symbol of mateship, intrepidness, coloniser - colonised reconciliation" (During, 1998: 35). Inclusiveness towards Māori and Pacific players, but also those from various 
social and economic backgrounds, is offered as evidence for the irrelevance of class demarcations. These ideas of 'classlessness' and an associated 'mateship' have deep historical roots, embedded in New Zealand's early national culture. Contrasting directly with Britain's perceived class distinctions (Pearson, 2013), early settlers aspired to build a nation characterised by possibilities for land ownership and social mobility for all (Wilkes, 2004). This notion was also maintained within discourses about schooling: "In New Zealand there is no selection at all for secondary education, and, within the State system, every child, whatever his ability is free to go to the secondary school of his choice" (Beeby, 1956: 396). As the country matured, it became perceived as a 'social laboratory', delivering forward thinking, progressive, egalitarian policies - including being the first nation to achieve women's suffrage, to introduce pensions and to create a welfare state based on Keynesian economics (Philips, 2014).

Similar historical narratives emerged in Australia. Despite its penal colony origins, rather than a regimental status and hierarchy of a 'total institution', the 'national character' was premised on a "...foundation of loyalty, respect, and fairness between individuals" (Greig et al., 2003:167-168). Ideas of 'fairness' and 'equity' came to pervade everyday language and the country's legal framework, leading to perceptions that Australia was the land of the 'fair go', an open society where hard work permits social mobility, even for the underdog (Greig et al., 2003). In both Australia and New Zealand these perspectives have become embedded into the national psyche and remain influential in shaping the public discourse today. This underscores views that both countries are progressive meritocracies where class and other social divisions have been avoided, despite evidence to the contrary.

Notions of meritocracy and class divides were always present in the settler societies of both countries, though not always easily discernible. A tendency towards 
self-employment, farming and trades in both countries obscured class stratification (Thrupp, 2001); yet, a new class system was being established as the nation state took hold. In Australia, as urbanisation and international trade escalated and the country entered into a modern capitalist world of trade, a more complex division of labour emerged featuring a new urban working class alongside a local mercantile capital class (Connell and Irving, 1980). Ethnic-class differences also quickly emerged in both states following discriminatory colonial practices of stealing land from indigenous Māori and Aboriginal and Torres Strait Island groups. This created a gendered and raced class structure with a small number of European landowners taking possession of large farming areas. For example, large numbers of Māori, alongside other settlers, were employed as either domestic workers, farm hands and labourers on the land or working in small industries in urban centres.

From the mid-1900s, emerging inequalities which undermined claims about Australia and New Zealand being egalitarian came under closer scrutiny. For example, in New Zealand, after substantial struggle by Māori in the 1960s and 70s, the state began to recognise its responsibilities to the Treaty of Waitangi ${ }^{1}$ and established not only the Waitangi Tribunal in 1975 that aimed to address the injustices of colonialism, but also by the 1980s began to recognise itself as 'bicultural'. Subsequent political (and academic) debates in New Zealand tended to concentrate on levels of inequality between Māori and Pākehā, ${ }^{2}$ giving more attention to 'white privilege', while marginalising class (Poata-Smith, 2004). That said, New Zealanders continue to use a 'we are all equal here' narrative; though, as Littlewood (2017) argues, equality appears to matter much more in terms of opportunity, not outcome. In fact, evidence shows that

\footnotetext{
${ }^{1}$ A treaty signed in New Zealand at Waitangi on February 6, 1840 by the British Crown and various Māori chiefs, resulting in the declaration of British sovereignty over New Zealand.

${ }^{2}$ A Māori term to describe early white settlers and their descendants who are not Māori.
} 
contradictions continue to exist within public opinion. For example, while New Zealanders persistently claim concern about equality, a strong resistance remains to policies and practices perceived to 'privilege' Māori. This continues despite strong evidence showing Māori disadvantage is not of their making, but, rather, due to past colonial practices (Littlewood, 2017). Against this backdrop, outlined here, the work of sociologists have helped to explore and set the agenda in studies of social class. In this paper we are particularly interested in young people's relationship to social class, arguing that in many ways they are a litmus test for society in that their experiences speak acutely to current and future social change. In the following section we review the changing nature of sociological approaches to class in youth studies before we layout our proposal to deepen research in this field.

\section{Class and Youth Sociology}

Approaches to studying class in the antipodes are historically connected closely with the northern hemisphere, with New Zealand and Australia seen as extensions of the British territories (Connell, 2007). For example, Woodward and Emmison (2009) suggested that the history of class theorising in Australia has had three strands. First, stratification research oriented in a Marxist tradition; secondly, a quantitative tradition based on large social surveys and statistical methodologies; and finally, it was strongly influenced by the work of Erick Olin Wright and the neo-Weberian sociologist John Goldthorpe. This led to opposition to 'abstract empiricism', arguing instead for a stronger focus on the social survey to identify trends and patterns. Several studies between the 1970s and 1990s applied such an approach and these showed that class held relevance in both Australia and New Zealand. For instance, in the early post-war 
period statistical modelling of school-to-work movements predominated, showing countries such as Australia to be divided by class and gender (Connell et al, 1957). Interestingly, in the UK some of the more radical work that developed in the 1970 s and early 1980 s on class emerged through the study of youth. A major classed approach came through the Marxist theorising of social reproduction (Hall et al, 1978). This approach was primarily led by cultural studies researchers within the Birmingham School, who explained how working class boys learnt to be working class men (Willis, 1978), and how social change created 'magical solutions' that failed to alter the structural realties of young people's lives (Cohen, 1978). This research also spilled over into work analysing significant changes occurring in 'school-to-work' transitions and how class was being socially reproduced in what was seen as the new 'training state' (Mizen, 1998). By the 1980s, following these UK developments, Australian youth sociology evolved, undertaking cultural analyses of class reproduction by examining schools and training in particular (Connell, 1983). Until the early 2000s, little work emerged from New Zealand on youth and class but class analysis in Australian youth studies remained important. For example, Wyn and White (1997) dedicated a whole chapter of their book to the concept's importance for youth studies, arguing that '...it is important to bring class analysis to bear on the study of young people because class is so central to individual development and the collective experience' (1997: 33).

Yet, by the late 1990s, class theorising was also under attack across the northern hemisphere from the rise of post-modernist arguments suggesting that 'class was dead' (Pakulski and Waters, 1996), or a 'zombie category' (Beck \& Beck-Gernsheim, 2002: 201-2013) that lacked analytical purchase in a changing social context. Beck (1992) for example suggested that the new logic of societies focussed on how to manage risks, such as global warming, nuclear disaster, and food contamination; class was held less 
significant to how risk is to be managed. In this context, Beck argued that 'risk society' gave rise to the '...demolition of the large-group categories of industrial society as the fonts of identities, life situations and inequalities' (Atkinson, 2010: 18). Instead, Beck argued there was widespread individualization: people becoming disembedded from social forms and 're-embedded' in new ways, forced to 'cobble together their biographies' (Beck, 1992: 95).

Although writers such as MacLeod and Yates (2006) wanted to keep class on the agenda, by the mid-2000's class analysis virtually disappeared from Australian and New Zealand youth sociology. Writing in 2004, Wyn and Harris highlighted the growing need to explore alternative approaches in Australia and New Zealand suggesting that youth researchers, problematically, '...continue to interpret the lives of young people with references to orthodoxies and norms of the past' (2004: 282) and argued that 'established theoretical traditions' of particular nations create 'closure', limiting the possibilities of other approaches. While not explicitly criticising social class theory, this implied that youth sociology in Australia and New Zealand required fresh approaches that recognised both the local context and the ways that social change reconfigured young people's lives.

Henceforth, Australian youth sociology led in developing more diverse frameworks and new emphases, in particular upon changing subjectivities and identity work that prioritised the voices of the young. The concept of 'social generation' emerged as a conceptual framework offering alternative ways of reading and analysing social change (Wyn and Woodman, 2006), often relegating class to the margins (France and Roberts, 2017). Work on 'new' feminisms (Harris, 2004), multiculturalism and citizenship (Harris, 2013) and global youth (Nilan and Feixa, 2006) also emerged from Australia. Not only was class given less attention in these studies, it was also under attack by 
some as being a 'zombie category' that lacked analytical nuance to theorise and understand Australia's changing social context (Woodman, 2009). While New Zealand youth sociology has limited impact outside of the sociology of education, an exception to this work was the Youth First project, which explored Māori youth in rural areas, employing a strong focus on economic and structural reform in the nineties (Smith et al., 2002). More recently, The Children of Rogernomics (Nairn et al., 2012) primarily applied a social generational perspective to examine changing attitudes and choices young people make upon leaving school.

The broader study of class has also been resurgent, particularly in the UK (e.g. Skeggs 2004; Atkinson 2010; Savage 2015). In Australia and New Zealand, it has had less influence partly because the 'class is dead' thesis and 'choice biographies' gained substantial foothold. That said, a small number of general sociological studies in Australia have maintained the importance of class analysis through a focus on culture (e.g. Pini and Previle, 2013; Sheppard and Biddle, 2017). Other publications emerging in the last few years also pay more sustained attention to youth and social class. For example, Threadgold $(2011,2017)$ has persistently kept social class on the agenda in his work on social inequalities and his new book, Youth Class and Everyday Struggles, is an excellent example of how class operates to structure the lives of Australian young people's everyday lives in 'new times', across the middle-working class spectrum. Meanwhile Borlagdan (2015), without using the language of class, has drawn attention to how young people from higher income backgrounds are better positioned to manage risk and uncertainty than their working class counterparts.

\section{Towards a new agenda in youth sociology}


While, as above, we recognise that there is some evidence of a desire in youth sociology in the antipodes to 'put class back on the map', the marginalised position of class analysis of youth in these debates leads us to consider that a new research agenda is needed for youth sociology. Our first premise is that the concept of 'class' must be given due recognition in analyses of young people's lives. It is well acknowledged that 'inequality' and 'poverty' remain core concerns in the antipodes, yet how class contributes to these processes and experiences is usually ignored. It may be the case that how class operates in contemporary society is 'invisible' and difficult to identify, yet this is no reason to deny its existence. For example, in New Zealand recognition is given to that Māori and Pacific groups are highly disadvantaged by their colour and colonialism (the power of white privilege), but there appears to be reluctance to recognise the impact of class position on their experience and life chances (Borell et al., 2009).

Secondly, recognising that in the antipodes we lack reliable and systematic objective data that can support the growing body of subjective work of class, we suggest that a much broader and larger body of data in this area is needed. As critical sociologists, we are cautious of the development and handling of large scale data sets that attempt to measure class, yet we also recognise how important such an evidence base could be to measure social mobility and related aspects of class. The usefulness of this can be seen in the UK, where government has key measures built into the General Household survey that allows organisations such as the Social Mobility Commission to both monitor and evaluate levels and dynamics of class mobility. Similarly, the evidence from the 'Great British Class Survey' (Savage et al, 2013) has created new invaluable data that is leading to enhanced understandings of social class today and has generated significant debate about the relationship 
between class, inequality and poverty in the UK. A more recent study of UK elites that assess key documents over 100 years shows the significant advantages of private school attendance through a person's lifetime (Reeves et al. 2017). Developing such approaches in the antipodes would be invaluable in making class visible.

In the antipodes, we have limited data offering such close attention to measures of class, although the work of Savage et al (2013) has had an influence in Australia. For example, the empirical work by Sheppard and Biddle (2017) replicated this approach, using a combination of self-reported class, occupation level and latent class analysis to construct measures, with the latter identifying six class types in Australian society. These are based on the distributions of cultural, social, and economic capital among respondents although the authors note, that much more work is required on its analysis in respect of theorising class in Australia. Yet, few data sets exist that create and construct measures of class in the antipodes; even categories such as 'social and economic status', that might be seen as a proxy for class, are given limited attention in the analysis of many social trends that reflect class dynamics. For example, Chesters' (2015) analysis of intergenerational mobility in Australia explored the impact of education on different social economic status groups. While the results illuminate significant differences, especially for matureaged students, the notion of 'class mobility' is not alluded to in any significant way, only phrases such as; the 'movement up the social hierarchy', 'increased occupational prestige', 'higher earnings' or 'improved social status'. Similarly, in New Zealand concern, both politically and academically, about class social mobility is given limited attention. Measuring class and mobility between classes in New Zealand is highly problematic as quality robust data that is collected regularly and is 
assigned to a form of classification that acknowledges class is missing. Even when used these measures fail to acknowledge how relations between people are shaped by class, and how class in turn serves to enable or constrain people, their aspirations and outcomes. Measures of socioeconomic status also fail to acknowledge that people 'make their own history, but they do not make it as they please; they do not make it under circumstances chosen by themselves but under circumstances directly found, given and transmitted from the past...' (Marx, 1978: 595).

Thirdly, there remains limited work within youth sociology over the intersections between class and other areas of inequality (France and Roberts, 2017). This is particularly relevant in the antipodes over the class position of indigenous populations in Australia and New Zealand. For example, issues of privilege have tended to concentrate on how 'white privilege' advantages certain groups in New Zealand and Australia without locating this or giving attention to the classed nature of this relationship ${ }^{3}$. Similarly, we would suggest more work needs to be developed that looks at the intersections of youth, class and gender. Again, there remains limited work in this area (see France and Roberts, 2017) and an intersectional approach that tries to capture the way class operates across diversity is critical to any future youth sociology research agenda in the antipodes.

Our fourth and main proposal for a new research agenda in youth sociology, is that we must broaden our lens to develop a research programme that also highlights the invisible actions of the few; that is, the privileged - this is one of the key groups that remains overlooked as a result of the marginalisation of class within sociology. Indeed, mainstream sociological work on class has been criticised for

\footnotetext{
${ }^{3}$ Seee Poata-Smith, 2004 for a discussion on how such an analysis could bring added value to our understanding of Māori in New Zealand
} 
concentrating on 'the problematic of the proletariat' at the expense of the elite (Savage, 2015: 224). Sociology gives far less attention to the 'super rich' or elites or even the middle class ${ }^{4}$, and youth sociology has for the most part been interested in the 'marginal', 'disadvantaged', 'excluded' or 'poor' (Roberts, 2011). The main exceptions in respect of young people most often emerge from the sociology of education's interest in how middle class parents access and gain advantage in the education system (Ball 2008). Other work has attended especially to how the parents of girls position them for a future life of advantage (Maxwell and Aggleton, 2016), or researched how class privilege operates for young people in the Australian schooling system (McCarthy and Kenway, 2014). In New Zealand, Stephen and Gillies (2012) have examined how privilege worked for girls in the independent sector. This work starts to increase our understanding of the processes used by the wealthy to advantage their children, but there has been a tendency to focus attention on the compulsory schooling system. Given the reconfiguring of school-to-work transitions, youth sociology, we argue, should turn the lens to how the wealthy, the advantaged and the privileged not only maintain their own position but also socially reproduce their class futures for their children by transferring wealth, and cultural and social resources across generations and how these processes operate more dynamically into and beyond post-compulsory school environments.

\section{Understanding and researching privilege}

Despite interesting work in areas such as social psychology showing that wealthier class background correlates with elevated levels of narcissism and selfentitlement (Piff 2014), mainstream sociology has given little attention to the rich and 
wealthy when theorising class. A few excellent accounts do exist; for example, Sayer's (2015) explication of how the 'rentier class' amass unearned income from charging materially less advantaged populations to use desired and needed existing assets such as land, buildings, technology, or money. This wealth then becomes inheritance windfalls, 'trickling' down in unearned fashion to the children of the rich (Picketty 2013). Meanwhile, Reeves et al (2017) have drawn on 120 years of data to show the persistent function of 'elite' backgrounds in fostering access into elite occupations in the UK. Yet, 'studying up' remains rare (Williams, 2012), particularly as this applies to the character and operation of privilege.

The concept of privilege in the antipodes has concentrated particularly on the (very real) question of 'white privilege', especially in relation to the issue of colonialism in New Zealand. Borell and colleagues (2009) for example argue that Pākehā privilege has played a pervasive but silent role in the perpetuation of inequalities in New Zealand, made possible because cultural beliefs, practices, institutions and processes were introduced to benefit Pākehā. These authors further note that disparities between Māori and Pākehā in wealth and income, education, employment and health illustrate how privilege is deep-seated across a broad range of domains.

Privilege has been conceptually under theorised, yet several key characteristics are generally agreed upon. First, privilege refers to advantages afforded to particular groups in society that are unearned and invisible (Nenga, 2011; Pease, 2010). Second, privilege works to the advantage of those who benefit from it at the expense of those who do not (Rashbrooke, 2015). Finally, privilege is a systemic resource distributed via the discursive norms of institutions (Nenga, 2011). In this sense, the common theorising of privilege is a part of broader discursive practices existing within institutional and structural settings which invariably manifests itself in our political and legal institutions 
(Pease, 2010). Critically, understanding how the institutionalisation of privilege occurs in a society helps to explain the continuation of social inequality. In part, privilege is so powerful because it is a silent process. The rhetoric of meritocracy and good fortune are imbued within the dominant discourses operating in society, allowing those who benefit most to ignore the structural forces shaping the distribution of resources and opportunity (Borell et al., 2009).

While the invisibility of privilege is central to its relative absence in youth sociology in the antipodes, there exist various other associated methodological reasons. A significant factor is, as much research finds, that many people are reluctant to identify as privileged or wealthy, often preferring to name others holding greater levels of wealth than themselves (Rashbrooke, 2015). This reluctance results in researchers searching for proxies to name elites in society - such as housing location, occupations, schools and indications of assets. For example, many researchers in youth studies have examined private schooling as a proxy for wealth (e.g. Kenway \& Koh, 2013; Maxwell \& Aggleton, 2016). Such proxies for privilege are useful and necessary, but this practice can serve to conflate or camouflage privilege with other factors, thus reducing the significance of privilege as an entity in itself. Private schooling can give one measure of elites in society but can also overlook heterogeneity among young people attending private schools.

A further methodological issue relating to the invisibility of privilege and class in youth sociology is the difficulty of gaining access to privileged participants, especially outside the context of private and elite schooling. Discussions about wealth and privilege with young people can be problematic as many who will inherit wealth may not yet have any consciousness of their wealth at a young age (Reay, 2005), resulting in under-reporting or lack of self-identification of privilege. Yet, class has a 
powerful effect on the ways individuals engage as participants. In her study of privileged young people, Allan (2012) found participants exhibiting high levels of agency were able to negotiate their positioning in research differently, including guarding themselves from critical inspection. The agility with which these privileged young people used digital technology led Allan to conclude that her photography methodology was a form (in Bourdieu's words) of 'class making' in itself.

One final challenge in researching privilege is the 'personal cringe' that might be evoked, with many university researchers fitting the category of affluent middle class - this was the experience of researchers who, in examining white middle class identities in England, described how their research on the middle class provoked uncomfortable reflections:

' $\ldots$ they (the left-wing, pro-welfare white middle classes) are not 'the other', they are ourselves with all that brings in terms of desires, defendedness and attempts at dis-identification. (Reay, et al., 2011:167)

We therefore suggest that more intentional and innovative methodological strategies to examine class are also needed in youth sociology, and in particular, these need to be equipped to consider the inter-sectional and complex ways that class manifests itself today. With these challenges in mind, we turn our attention in the final section of the paper to highlight aspects of privilege that merit deeper exploration when examining youth and social class. We draw on Bourdieu's theoretical framework to show how this provides a way to understand the relational nature of privilege and how it reflects not only an individual's wealth, but also access to institutional, social and intergenerational attributes of families within a specific field. Relatedly, we outline an intersectional approach to understandings of class - which are also closely tied up with aspects of gender, ethnicity and geography. 


\section{Bourdieu and privilege}

Measuring economic levels of wealth is one way to approach the study of privilege. Job occupation, qualifications and professional status could further assist, and these have been traditional proxies of wealth in society. However, this approach is ineffective for studying youth as the young are generally neither fully qualified, nor individually holders of considerable wealth. Young people's privilege is more 'invisible' than adults, and thus requires much more careful measures and assessment. Further, as we discussed earlier, privilege has often been narrowly defined as socio-economic status or economic wealth, thus overlooking the wider symbolic struggle of class (Savage, 2015), and the ways it is manifested through institutional, employment and intergenerational structures. Here, we detail three aspects of privilege that warrant further investigations, recognising the relational qualities of class through Bourdieu's theory of practice (Bourdieu, 1990).

Bourdieu's theory of practice has primarily been used to explain how patterns of poverty emerge and are reproduced in society. We suggest that his theory also has highly valuable insights for the study of privilege. Through his conceptual triad of capital, habitus and field, Bourdieu's theory of practice provides an explanatory framework for how privilege is created and maintained. He sees this happening in several ways. Firstly, individuals and groups are continually engaged in struggles within 'fields' for resources and for gaining advantage. Fields '...denote arenas of production, circulation, and appropriation of goods, services, knowledge, or status, and the competitive positions held by actors in their struggle to accumulate and monopolize these different kinds of capital' (Swartz, 1997:117). According to Bourdieu, capital is then central to this process being the resources actors take and use within the field. While economic capital 
is perhaps the easiest to observe, Bourdieu's addition of social capital (the networks of relationships and connections) and cultural capital (assets which provide knowledge and knowing) are crucial for explaining young people's positioning. Specific forms of capital gain higher symbolic status when it is recognised within a certain 'field'. As a result, those who have greater access to these forms of capital (such as the 'rulingclass', the elite and the high achieving middle class) are more likely to be winners. For them, 'knowing the rules of the game', what counts as important and 'how it is played' ensures their position is maintained and continues unchallenged.

Secondly, central to Bourdieu's approach is a critique of domination and how it operates in modern societies. He sets out to uncover how social order masks and perpetuates domination through what he calls symbolic violence or 'the subtle imposition of systems of meaning that legitimize and thus solidify structures of inequality.' (Wacquant, 2006: p262). This he argued has the capacity to impose meaning and value on particular forms of social practice that legitimises the unequal nature of relationships and power. Bourdieu would also remind us that such taken-forgranted constructions of reality can be part of the process of domination. He uses the term 'doxa' to illustrate this point suggesting it is. '... a particular point of view, the point of view of the dominant, which presents and imposes itself as a universal point of view...' (Bourdieu, 1998:57). As a result, he suggests symbolic violence operates to ensure that the dominated accept their own domination as legitimate (Bourdieu and Wacquant, 1991).

In the following examples we suggest that, in times when the young are struggling to access resources and to navigate their pathways to independent adulthood (France, 2016; France and Roberts, 2017), Bourdieusian analyses of the wide range of social processes that are at work in the critical fields where young people struggle for 
resources can illuminate the way that privilege works for the few. In this we show how the institutionalisation of privilege warrants further interrogation, otherwise privilege is simply rendered invisible and assumed (and claimed) to be won through individual meritocratic acts.

\section{The 'field' of education and privilege}

Our first example relates to the field of education and how accessing the 'best' schooling arises as a result of privilege. Firstly, it is well recognised that the compulsory education system gives significant advantage to the middle class through their navigation of the school zoning system (Thrupp, 2008). Significant to this success is the application and usage of economic capital and financial assets. Hansen (2014), for example, shows that parents happily pay substantially more to purchase a house located near to better-performing primary schools, even before their children reach school starting-age. This confirms Stephens and Gillies' (2012) New Zealand study, which showed how this process starts at a very early age via access to either the best or worst kindergarten. Those with more economic capital were able to transition their children from kindergarten into the 'right' schools. Yet not all parents are able to get their children into such schools, but as Stephen's Ball (2008) work on how middle class parents develop strategies for their children in the English schooling system shows, advantage and privilege can and does arise as a result of parents being able to mobilise their social and cultural capital in less successful schools by ensuring their children have access to the best resources and are given special attention.

Access to private and elite schooling is also strongly influenced by economic capital, but Bourdieu also recognises this as a dynamic process of establishing advantage that relies on a competitive field of distinction. The ability to pay tuition fees 
to access the best independent or private schools is a form of public withdrawal that is well entrenched in Australia (and New Zealand to a lesser extent), ensuring not just large and significant differences in school tuition costs between regional and metropolitan areas and between state territories, but also between public, catholic and private provision (Campbell et al 2009). For example, in Australia Catholic school education fees are typically three-four times higher than state schools, while private education costs around eight times that of a state education. Elite schools by their very design, of course, are preoccupied in many ways with the maintenance of already entrenched advantage (Kenway, 2013). But it is the mix of public and private and high and low status of schooling that allows some schools to emerge with 'distinction' (Bourdieu, 1984) to ensure those from privileged backgrounds continually gain advantage within the compulsory education system and into future jobs. As Kenway (2013: 303) reminds us in the Australian context, there is a '...funnelling of a disproportionate percentage of students from the independent school sector into mental labour and a disproportionate percentage of students from the government sector into manual labour'. Being privately educated therefore continues to give advantage at tertiary education by providing a premium over and above that derived from a degree.

It is clear that the education system remains unfair - giving advantage to those who are best placed to gain from it. This clearly reinforces the value of Bourdieu's concept of symbolic violence. We must ask the question why, given the depth of knowledge that the system perpetuates inequality, is there so little action to address it? Bourdieu argues that the dominant class have the power and ability to maintain and justify such a practice while those who are dominated accept it as 'natural', '...When you ask a sample of individuals what are the main factors of achievement at school, the further you go down the social scale the more likely they believe in natural talent and 
gifts' (Bourdieu and Eagleton, 1991: 111). The result is that privilege is ignored and not seen as important in how educational opportunities are distributed.

\section{The 'field' of paid employment and privilege}

Our second example surrounds how class privilege operates in the field of paid employment. Having a good secure job with career prospects and opportunities to earn more are increasingly critical for a person's long-term health and well-being, and these also contribute to a person's class position even in times of uncertainty (Savage, 2015). During economic uncertainty, jobs are harder to get and competition for access to the best jobs increases (Brown et al, 2011), but graduates from high prestige universities tend to be more successful in the labour market. This is not simply a process of having had the best start (although, as we show above, this is a critical feature), or having a particular habitus but also results from how the system structures and recognises certain forms of capital over and above others.

In contemporary times, new forms of cultural capital are emerging (Savage, 2015) that give weight to certain activities that are more accessible to the middle and elite classes. First, it is clear that having a degree today is insufficient to be competitive in the labour market. With graduate numbers outstripping high quality jobs (France, 2016) young people must develop alternative strategies to get noticed. One such approach is the creation of a more dynamic and positive CV supplemented by high quality volunteering or travel. For example, traditionally, the gap year was seen as a time to have 'fun' and 'adventure', but in this competitive environment it is instrumentally, purposively positioned as an important part of the process of $\mathrm{CV}$ building as it can be a major source of cultural capital and also establishes strong social networks that can be developed later in life. In New Zealand, the 'OE' (overseas 
experience) is positioned as a national ritual. It is popularised as 'something that everyone does', yet in reality it is a classed practice, open only to those who have adequate resources and family support (Haverig and Roberts, 2011). These experiences are supplemented further through young people's networks of social capital which enable the privileged to access strategic contacts within industry who often acts as brokers for initial job interviews (Kenway and Koh, 2016).

Another such example of the nature of privilege and job markets can be seen in the growing influence and role of internships (France and Roberts, 2017)). Evidence shows that those having done internships increase their opportunities to get into well paid work (Intergenerational Foundation, 2014). In this sense it becomes a part of the new cultural capital that has high symbolic status. Grugulis and Stoyanova's (2012) UK study of the film and TV industry is a good example of how this works, showing how white middle-class men ensured that middle class signals become the proxies for the most sought-after jobs and that graduates from middle class backgrounds were able to use their networks and cultural capital to access them. A recent Australian study (Oliver et al., 2016) found unequal access to unpaid work experience, and that the costs of taking part would fall most heavily on young people from lower class backgrounds. Similarly, it has been shown that those promoting internships target the 'best' universities ensuring that those from the middle classes and from more privileged backgrounds are more likely to get first option on the best opportunities (Intergenerational Foundation, 2014). Much more extensive research in these areas is required if we are to understand the complexity of the intersection between employment and privilege and the lives of young people.

\section{Intergenerational wealth and youth}


Finally, recent evidence shows how the state actively supports the maintenance and expansion of wealth inequality and we should acknowledge the importance of this in the process of building and maintaining privilege. Evidence from Australia shows how the tax and transfer system operates across different income quintiles in Australia showing '.. that the bottom $20 \%$ of Australians receive just $\$ 6.1$ billion in such benefits, while the top $20 \%$ receive ten times as much, at over $\$ 68$ billion.' (Dawson and Smith (2018:6). Yet this 'invisible hand of the state' is given little (or no) attention in debates about the causes of inequality between the rich and poor (Dawson and Smith, 2018).

What we also see is the 'invisibility of privilege' embed in discourses on how people 'become' wealthy. The dominant idea that emerges in the media is that wealth ownership is a result of 'hard work'. The notion that privilege (or state financial processes) are operating is generally dismissed by claims that we live in an 'open society' where anyone who takes the opportunity can be successful. It is not unusual to see this continually justified and reinforced in the media with stories that show individual young people who have made their fortune by their early 20 s. The example of Mark Zuckerberg, the Facebook creator, is often mobilised as an example, alongside others, over what is possible. Yet, what is not elaborated in the case of Zuckerberg or other successful entrepreneurs is the financial support they may have received or inherited. For example, Zuckerberg comes from a very wealthy background and that this helped him get into Harvard; his parents invested highly in his education and while he took his opportunities he was highly privileged which helped underpin his success. This discourse denies privilege and promotes again the idea that success is a 'natural' process at work. As Bourdieu reminds us, this process is a form of symbolic violence that is promoted by the wealthy as a social fact, reinforcing the right of the powerful and privileged to maintain their position uncontested. 
A second way this works for the young today is through intergenerational wealth transfer (through posthumous and 'in life' familial inheritance). This is central to reproducing privilege between generations. Recent New Zealand research shows that by age 38, inequalities of wealth ownership between social groups are well established in contrast to many other countries where this occurs much later in life (Chapple et al., 2015). In 2011, New Zealand's government made this process easier by removing taxation from 'gifts' or transfers of wealth to children. Yet, while inheritance of wealth is crucial, intergenerational social reproduction of privilege is also achieved through other subtler intergenerational mechanisms.

Beyond financial wealth, privileged young people also operate with a habitus that enhances and reproduces privilege often in small, everyday ways. Reay (2005) for example, reminds us that class-based identities are made and remade at the micro level, in and through innumerable practices, serving to reproduce structural inequalities for children and young people and maintaining levels of social exclusion. Skeggs (2004: 1009) describes how through this process of class enactment, 'entitlements and judgments of culture are put into effect and authorized' through marginalised young people's feelings of ambivalence, inferiority and superiority, visceral aversions, and the markings of taste.

Conversely, young people from privileged backgrounds can match this process effortlessly - in their language, deportment, confidence and ease - while others feel like a 'fish out of water' in such contexts. The intergenerational and family-based processes which contribute to this embodied capital and habitus contain 'concealed intergenerational processes that serve to reproduce socio-economic advantage, disadvantage and privilege' (Holt, 2008: 234). The cumulative and exchangeable properties of capital mean that these processes of advantage and disadvantage are 
likely to exacerbate further as young people move into adulthood. Diprete and Eirich (2006:272), for example, identify a body of research that shows how 'the advantage of one individual or group over another grows (i.e., accumulates) over time, which is often taken to mean that the inequality of this advantage grows over time'. How this occurs in Australian and New Zealand schools has rarely been studied - something that must be remedied - but it is likely to play out in ways which ensure that class advantage and privilege is, as we have seen is 'cumulative'.

\section{Conclusions}

Our central argument has been for a widening of the youth research agenda to include a more explicit focus on class and privilege, and to thereby gain greater insights into the experiences of young people and inequalities. We propose that not only does class matter, but also that understanding how privilege amongst the middle classes and the elite operates across Australia and New Zealand needs to be centralised in any analysis of class. As we have argued, the notion of classlessness in the antipodes while being embedded in the 'public imagination' is a myth.

The idea of classlessness in the antipodes therefore operates as a form of symbolic violence that gives justification to the existing system re-enforcing the status quo as 'natural'. Such practices can have embedded in them counterperspectives that not only justify inequality to be normal, but to construct the problem in ways that detract attention from how privilege manifests. For example, in New Zealand 'privilege' particularly in the actions of the state, is constructed, by the dominant class, as giving advantage to Māori (Matthewman, 2017). Such a perspective, while being a myth, then operates to refocus the debates on privilege in ways that avoid serious interrogation of how the dominant maintain their position and 
ensure their young continually accrue advantage. As our examples have showed, these practices in education and employment fields remain entrenched and, over time, cumulatively ensure advantage for certain groups of young people over others. We recognise this process is not a new sociological discovery, and indeed this is part of our main point. Almost half a decade ago, for example, Goldthorpe ([1969] 1974: 218), writing in the British context, noted that 'the members of the higher strata have the motivation and, in general, the resources to hold on to their power and transmit it to their children', defining the power to do so as 'the capacity to mobilise resources'. Yet, we contend that in recent times in youth sociology in the antipodes, this process lacks proper scrutiny; we thus propose that further research and theorising of how class privilege works is essential for youth sociology, and that a Bourdieusian approach can facilitate the required scrutiny. 


\section{References}

Allan, A. (2012). Power, Participation and Privilege - Methodological Lessons from Using Visual Methods in Research with Young People. Sociological Research Online, 17, 8.

Australian Council of Social Services. (2015). Inequality in Australia; A Nation

Divided. Strawberry Hills, NSW: Australian Council of Social Services.

Ball, S. (2008). The education debate. Bristol, UK: Policy Press.

Beck, U. (1992). Risk society: Towards a new modernity. London: Sage Publications.

Beck, U., \& Beck-Gernsheim, E. (2002). Individualization. London: Sage.

Beeby, C. E. (1956). New Zealand: An example of secondary education without selection. International Review of Education, 2(4), 396-409.

Borell, B., Gregory, A., McCreanor, T., Jenson, V., and Barnes, H. (2009). It's hard at the top but it's a whole lot easier than being at the bottom, Race/ Ethnicity: Multidisciplinary Global Contexts, Vol. 3 29-50

Borlagdan, J. (2015). Inequality and 21-year-olds' negotiation of uncertain transitions to employment: a Bourdieusian approach. Journal of Youth Studies, 18(7), 839-854.

Bourdieu, P. (1977). Outline of a theory of practice. Cambridge: Cambridge University Press.

Bourdieu, P. (1990). The logic of practice. Stanford: Stanford University Press.

Bourdieu, P. (1984). Distinction: A social critique of the judgement of taste. London: Routledge \& Kegan Paul.

Bourdieu, P. \& Wacquant, L. (1992). An invitation to reflexive sociology, Chicago, The University of Chicago Press. 
Chapple, S., Hogan, S., Milne, B., Poulton, R., \& Ramrakha, S. (2015). Wealth inequality among New Zealand's Generation X. Policy Quarterly, 11, 73-78.

Chesters, J. (2015). Within-generation social mobility in Australia: The effect of returning to education on occupational status and earnings, Journal of Sociology Volume: $51(2), 385-400$

Connell, W.F., Francis, E.P. \& Skilbeck, E. (1957). Growing up in an Australian city: A study of adolescents in Sydney, Australian Council for Educational Research.

Connell, R. (1983). Which Way is Up? Essays on class, sex and culture (Sydney, Allen \& Unwin).

Connell, R. (2007). Southern theory: The global dynamics of knowedge and social science, Crows Nest: Allen \& Unwin.

Connell, R. W., \& Irving, T. H. (1980). Class Structure in Australian History:

Documents. Narrative and Argument, Longman Cheshire, Melbourne.

Dawson, E. and Smith, W. (2018). The Cost of Privilege, Canberra, Anglicare

Diprete, T. and Eirich, M (2006). Cumulative advantage as a mechanism for inequality: A review of theoretical and empirical developments, Annual Reviews Sociology, 32 p $271-97$

During, S. (1998). Postcolonalism and globalisation: a dialectical relation after all? Postcolonial Studies, 1, 31-47.

France, A. (2016). Understanding Youth in the Global Economic Crisis, Bristol, Policy Press

France, A. and Roberts, S. (2017). Youth and Social Class: Enduring inequality in the UK, Australia and New Zealand, London, Palgrave.

Greig, A., Lewins, F, and White, K. (2003). Inequality in Australia, Cambridge, Cambridge University Press 
Goldthorpe, J. (1974 [1969]). Social inequality and social integration in modern Britain, in D Wedderburn (ed.) Poverty Inequality and Class Structure. Cambridge University Press. Pp 217-237.

Grugulis, I., \& Stoyanova, D. (2012). Social capital and networks in film and TV: Jobs for the boys? Organization Studies, 33 (10), 1311-1331.

Harris, A. (2004). Future girl: Young women in the twenty-first century. Psychology Press.

Harris, A., (2013). Young People and Everyday Multiculturalism, Routledge, New York and London

Haverig, A., \& Roberts, S. (2011). The New Zealand OE as governance through freedom: rethinking 'the apex of freedom'. Journal of Youth Studies, 14(5), 587603.

Holt, L. (2008). Embodied social capital and geographic perspectives: Performing the habitus. Progress in Human Geography, 32, 227-246.

Kenway, J. (2013). Challenging inequality in Australian schools: Gonski and beyond. Discourse: Studies in the cultural politics of education, 34(2), 286-308.

Kenway, J., \& Koh, A. (2013). The elite school as 'cognitive machine' and 'social paradise': Developing transnational capitals for the national 'field of power'. Journal of sociology, 49 (2-3), 272-290.

Littlewood, D. (2017). 'We're all equal here mate' Egalitarianism in Aotearoa New Zealand, in Cain, T., Kahu, E., and Shaw, R. (2017) Tūranga Wae Wae: Identity and Belonging in Aotearoa New Zealand, Auckland, Massey University Press Matthewman, S. (2017). Pākehā Ethnicity: The Politics of White Privilege in Bell, A., Elizabeth, V., Mclntosh, T. and Wynyard, M. A Land of Milk and Honey? Auckland, Auckland University Press. 
Marx, K (1978). The Eighteenth Brumaire of Louis Bonaparte. Foreign Language Press: Peking.

Maxwell, C., \& Aggleton, P. (2016). Creating Cosmopolitan Subjects: The Role of Families and Private Schools in England. Sociology, 50(4), 780-795.

McCarthy, C. and Kenway, J. (2014). Introduction: understanding the re-articulations of privilege over time and space. Globalisation, Societies and Education, 12(2), 165-176.

Mizen, P. (1995). Young People, Training and the State: In and Against the Training State, Mansell, London.

Nairn, K., Higgins, J., \& Sligo, J. (2012). Children of Rogernomics: A neoliberal generation leaves school. Otago: Otago University Press.

Nilan, P., \& Feixa, C. (Eds.). (2006). Global youth? Hybrid identities. Oxon/NY: Routledge.

Oliver, D. McDonald., P., Stewart, A., \& Hewitt, A. (2016). Unpaid Work Experience in Australia: Prevalence, nature and impact, Canberra: Commonwealth Department of Employment.

Pakulski, J., and Waters, M. (1996). The Death of Class. London: Sage.

Pearson, D. (2013). Comparing cultures of decline? Class perceptions among English migrants in New Zealand. New Zealand Sociology, 28, 81-101.

Philips, J. (2014). 'Visitor opinions about New Zealand - the Social Laboratory of the World 1890 - 1920, Te Ara - the Encyclopaedia of New Zealand https://teara.govt.nz/en/visitors-opinions-about-new-zealand/page-3 
Picketty, T. (2013). Capital in the Twenty-First Century. USA: Harvard, Harvard University Press

Piff, P. K. (2014). Wealth and the inflated self: Class, entitlement, and narcissism. Personality and Social Psychology Bulletin, 40(1), 34-43.

Pini, B. and Previte, J. (2013). Bourdieu, the boom and cashed-up Bogans. Journal of Sociology, 49(2-3), 2256-271.

Poata-Smith, E. (2004). Ka Tika A Muri, Ka Tika A Mua? Māori Protest Politics and the Treaty of Waitangi Settlement. In Spoonley, P., Macpherson and Pearson, D. (Ed.), Tanata Tangata: The Changing Ethnic Contours of New Zealand. Southbank, Victoria: Dunmore Press.

Rashbrooke, M. (2015). Wealth and New Zealand. Wellington: Bridget Williams Books Ltd.

Reay, D. (2005). Beyond consciousness? The psychic landscape of social class. Sociology, 39(5), 911-928.

Reay, D., Crozier, G., \& James, D. (2011). White middle class identities and urban schooling: Identity studies in the social sciences. NY: Palgrave MacMillan.

Reeves, Aaron, Sam Friedman, Charles Rahal, and Magne Flemmen. (2017). "The decline and persistence of the Old Boy: Private schools and eliterRecruitment 1897 to 2016." American Sociological Review82 (6):1139-1166. doi: $10.1177 / 0003122417735742$.

Roberts, S. (2010). Misrepresenting 'choice biographies'? A reply to Woodman. Journal of Youth Studies, 13(1), 137-149. 
Roberts, S. (2011). Beyond 'NEET' and 'tidy' pathways: considering the 'missing middle' of youth transition studies. Journal of Youth Studies, 14(1), 21-39.

Roberts, S. (2012). One step forward, one step Beck: a contribution to the ongoing conceptual debate in youth studies. Journal of youth studies, 15(3), 389-401.

Savage, M. (2015). Introduction to elites: From the 'problematic of the proletariat' to a class analysis of 'wealth elites'. The Sociological Review, 63, 223-239.

Savage, M., Devine, F., Cunningham, N., Taylor, M., Li, Y., Hjellbrekke, J., and Miles, A. (2013). A new model of social class? Findings from the BBC's Great British Class Survey experiment. Sociology, 47(2), 219-250.

Savage, M., \& Williams, K. (2008). Remembering Elites, Oxford, Blackwell.

Sheppard, J., \& Biddle, N. (2017). Class, capital, and identity in Australian society. Australian Journal of Political Science, 1-17.

Smith, L. T., Smith, G. H., Boler, M., Kempton, M., Ormond, A., Chueh, H. C., \& Waetford, R. (2002). 'Do you guys hate Aucklanders too?' Youth: Voicing difference from the rural heartland. Journal of Rural Studies, 18, 169-178.

Sayer, A. (2015). Why We Can't Afford the Rich. Policy Press

Skeggs, B. (2004). Class, self, culture. London and NY: Routledge.

Stephens, S. and Gillies, A. (2012). Understanding the Role of Everyday Practices of Privilege in the Perpetuation of Inequalities. Journal of Community and Applied Social Psychology, 22, 145-158.

Swartz, D. (1997). Culture and Power, Chicago, University of Chicago Press. 
Threadgold, S. (2011). Should I pitch my tent in the middle ground? On 'middling tendency', Beck and inequality in youth sociology. Journal of youth studies, 14(4), 381-393.

Threadgold, S. (2017). Youth, class and everyday struggles. London: Routledge.

Thrupp, M. (2001). Education policy and social class in England and New Zealand: an instructive comparison. Journal of Education Policy, 16(4), 297-314.

Thrupp, M. (2008). Education's 'inconvenient truth': Part two - the middle class advantage. New Zealand Journal of Teachers' Work, 5, 54-62

Woodman, D. (2009). The mysterious case of the pervasive choice biography: Ulrich Beck, structure/agency, and the middling state of theory in the sociology of youth. Journal of Youth Studies, 12(3), 243-256.

Wyn, J., \& White, R. (1997). Rethinking Youth. London: Sage Publications.

Wyn, J., \& Harris, A. (2004). Youth research in Australia and New Zealand. Young, 12(3), 271-289.

Wilkes, C. (2004). Class, in Spoonley, P., Pearson, D., and Shirley, I. (eds.) New Zealand Society, New Zealand, Dunmore Press

Williams, C. (2012). Researching Power, Elites and Leadership, Sage. London.

Woodward, I. and Emmison, M (2009). The Intellectual Reception of Bourdieu in Australian Social Sciences and Humanities, Sociologica, 2 (3), 1-22 